\title{
Use of modified therapeutic upper endoscope for ERCP in patients post pancreaticoduodenectomy
}

\section{다(1)(우}

\author{
Authors \\ Institutions \\ 1 University of Minnesota Medical Center, Division of \\ Gastroenterology, Hepatology, and Nutrition, \\ Minneapolis, Minnesota, United States \\ 2 Minneapolis VA Health Care System, Division of \\ Gastroenterology and Hepatology, Minneapolis, \\ Minnesota, United States
}

Nicholas M. McDonald ${ }^{1}$, Mohamed Abdallah' ${ }^{1}$, Dharma Sunjaya ${ }^{1,2}$, Mohammad Bilal ${ }^{1,2}$

submitted 8.10 .2021

accepted after revision 3.3.2022

published online 4.3 .2022

Bibliography

Endosc Int Open 2022; 10: E905-E909

DOI 10.1055/a-1789-0238

ISSN 2364-3722

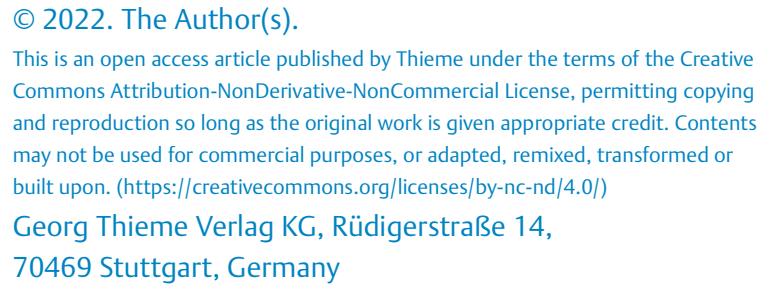

Corresponding author

Michael McDonald, Division of Gastroenterology, Hepatology, and Nutrition, University of Minnesota Medical Center, 500 SE Harvard St, MMC 36, Minneapolis, MN 55454-1400, United States

Fax: +1-612-625-5620

mcdon620@gmail.com

\section{Introduction}

Since the invention of endoscopic retrograde cholangioscopy (ERCP) in 1968, the procedure has continued to evolve and has become integral to modern management of pancreaticobiliary disease [1]. While ERCP is commonly performed, in patients with gastric or small bowel surgically altered anatomy (SAA), the procedure may pose substantial technical challenges, resulting in failure [2-6]. Common types of SAA posing unique challenges to ERCP include Billroth I gastrectomy, Billroth II gastrectomy, Roux-en-Y gastric bypass, and pancreaticoduodenectomy, also known as a Whipple procedure [2-6]. Anatomical challenges in ERCP for SAA are often associated with difficulties in intubation of the anastomosis, length of the biliopancreatic (afferent) limb, inability to cannulate the biliary tree through the anastomosis, lack of an elevator mechanism, or endoscope incompatibility with the required endoscopic accessories [2].

In cases of ERCP in patients with pancreaticoduodenectomy anatomy, multiple types of endoscopes have been used, with a traditional side-viewing duodenoscope being the most common [7]. Chahal et al have previously evaluated outcomes of ERCP in patients with pancreaticoduodenectomy. In their series of 88 patients with pancreaticoduodenectomy who underwent ERCP, they found a $51 \%$ technical success rate and low rates of adverse events (AEs) [7]. In this series, a conventional side- viewing duodenoscope was used in all the cases; in the $14.8 \%$ of cases in which the conventional duodenoscope failed in successful completion for ERCP, an adult or pediatric colonoscope was utilized.

Conventional ERCP with a side-viewing duodenoscope allows for therapeutic interventions including sphincteroplasty, stone extraction, tissue sampling, stent placement, and more [2]. Adult or pediatric colonoscopes offer the advantage of being forward-viewing, and the longer length makes it possible to reach the biliary limb. Other options include using balloon enteroscopy-assisted ERCP $[8,9]$. When a conventional duodenoscope cannot be used, each approach (adult and pediatric colonoscope, and balloon enteroscopy-assisted ERCP) has its advantages and potential limitations. Here we present our preliminary experience utilizing the newer modified therapeutic upper endoscope (1T; GIF-1TH190 Olympus, Center Valley, Pennsylvania, United States) for ERCP in patients with pancreaticoduodenectomy after a failed attempt with a conventional duodenoscope.

\section{Results}

\section{Case 1}

A 72-year-old man with a history of extrahepatic cholangiocarcinoma who underwent classic (non-pylorus sparing) pancreaticoduodenectomy 1 year prior and currently was on chemo- 
therapy with capecitabine and oxaliplatin presented with jaundice. Laboratory evaluation revealed a total bilirubin of $31.1 \mathrm{mg} / \mathrm{dL}$ (reference range $0.2-1.2 \mathrm{mg} / \mathrm{dL}$ ) and direct bilirubin of $22.6 \mathrm{mg} / \mathrm{dL}$ (reference range $<0.5 \mathrm{mg} / \mathrm{dL}$ ) which was elevated from 1 month prior, at which, time the patient had normal bilirubin levels. Magnetic resonance cholangiopancreatography revealed intrahepatic biliary dilation with an abrupt cut-off at the level of the hepaticojejunostomy suggestive of stricture or tumor recurrence, as well as peritoneal carcinomatosis. Given this, the patient was referred for ERCP. A conventional side-viewing duodenoscope was utilized; however, it could not be advanced to the biliary limb. A $1 \mathrm{~T}$ therapeutic upper endoscope was then used. The biliary limb was identified and confirmed with the presence of suture material. However, despite aggressive interrogation, the hepaticojejunal anastomosis could not be identified. A tattoo was placed for identification of biliary limb, 3 to $4 \mathrm{~cm}$ into the biliary limb. The decision was made to perform an endoscopic ultrasound-guided rendezvous to obtain biliary access. A linear echoendoscope (GF-UCT180 Olympus, Center Valley, Pennsylvania, United States) was used and a left intrahepatic biliary radical was identified and punctured using a 19-gauge fine-needle aspiration needle. Then, a 0.025 -inch and $450-\mathrm{cm}$-long straight guidewire was placed across the hepaticojejunostomy stricture and the echoendoscope was removed and the guidewire left in place. The $1 \mathrm{~T}$ therapeutic upper endoscope with a clear distal attachment cap was then inserted into the biliary limb and the hepaticojejunostomy was identified by viewing the guidewire entry point into the jejunum. The hepaticojejunal anastomosis was subsequently cannulated adjacent to the wire using a biliary balloon extraction catheter loaded with a guidewire. A cholangiogram demonstrated intrahepatic biliary dilation and focal stenosis at the level of the hepaticojejunostomy consistent with recurrent cholangiocarcinoma ( $\triangleright$ Fig.1). An uncovered metal stent $(10 \mathrm{~mm}$ in diameter and $4-\mathrm{cm}$ length) was placed, and the jaundice had resolved 8 weeks later at the time of last follow-up ( $\triangleright$ Fig. 2 ). The patient was admitted post procedure for observation and was discharged the following day without any procedure- or anesthesia-related AEs.

\section{Case 2}

A 64-year-old woman with a history of Gardner syndrome requiring colectomy with Kock pouch and classic (non-pylorus sparing) pancreaticoduodenectomy for an ampullary adenoma 10 years prior presented for follow-up of adenomatous tissue at the hepaticojejunal $(\mathrm{HJ})$ anastomosis. Total bilirubin was mildly elevated at $1.5 \mathrm{mg} / \mathrm{dL}$ (reference range 0.2 to $1.2 \mathrm{mg} / \mathrm{dL}$ ). She had previously been found to have adenomatous tissue at the hepaticojejunal anastomosis and had undergone endoscopic mucosal resection and intraductal radiofrequency ablation with resultant $\mathrm{HJ}$ stricture ( $\triangleright$ Fig.3). Due to the stricture, the bile duct could not be cannulated and required placement of an internal-external biliary drain by interventional radiology. When the patient returned for follow-up, after failure of a conventional side-viewing duodenoscope, a $1 \mathrm{~T}$ therapeutic upper endoscope was advanced to the $\mathrm{HJ}$ anastomosis and the biliary drain was visualized within the jejunum and fluoroscopically

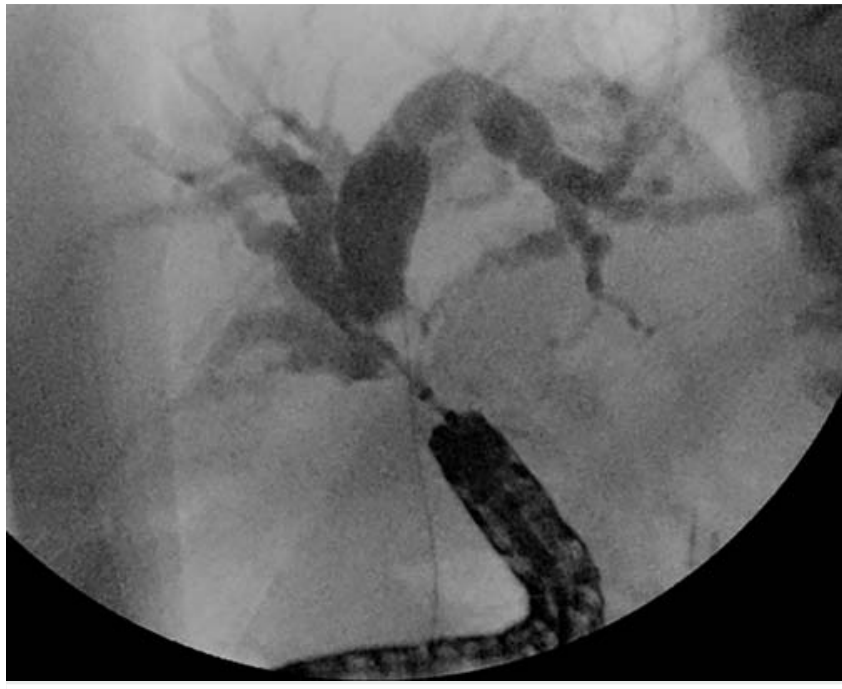

Fig. 1 Fluoroscopic view of dilation of intrahepatic biliary dilation extending to the hepaticojejunostomy.

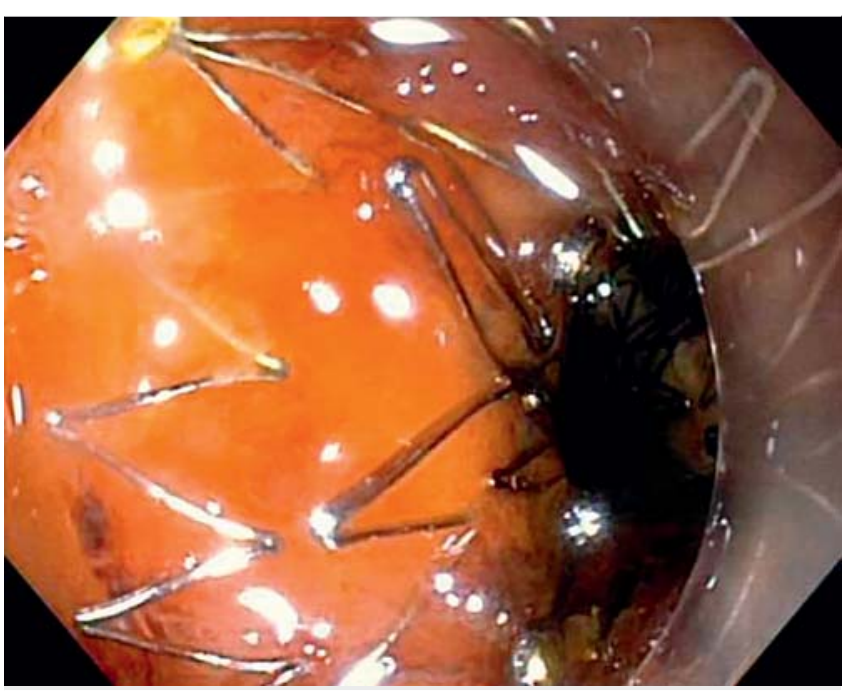

Fig. 2 Uncovered metal stent placed across the hepaticojejunostomy.

( $>$ Fig. 4 and $>$ Fig.5). The drain was removed by an interventional radiologist and a wire was placed across the anastomosis into the jejunum. Then, the wire was grasped with a snare and pulled through the working channel of the endoscope. A biliary balloon catheter was loaded over the wire and then advanced through the endoscope, allowing for successful cannulation. After balloon dilation of a 5-mm area of focal stenosis, the hepatico-jejunostomy was explored using cholangioscopy (Spyglass DS, Boston Scientific, Marlborough, Massachusetts, United States) through the $1 \mathrm{~T}$ therapeutic upper endoscope working channel. The cholangioscope was advanced to the hepatic duct bifurcation. Abnormal-appearing mucosa was seen from $2 \mathrm{~cm}$ distal from the hilum extending all the way to the $\mathrm{H}$ anastomosis ( Fig. 6). SpyBite max forceps (Boston Scientific, Marlborough, Massachusetts, United States) were used and biopsies 


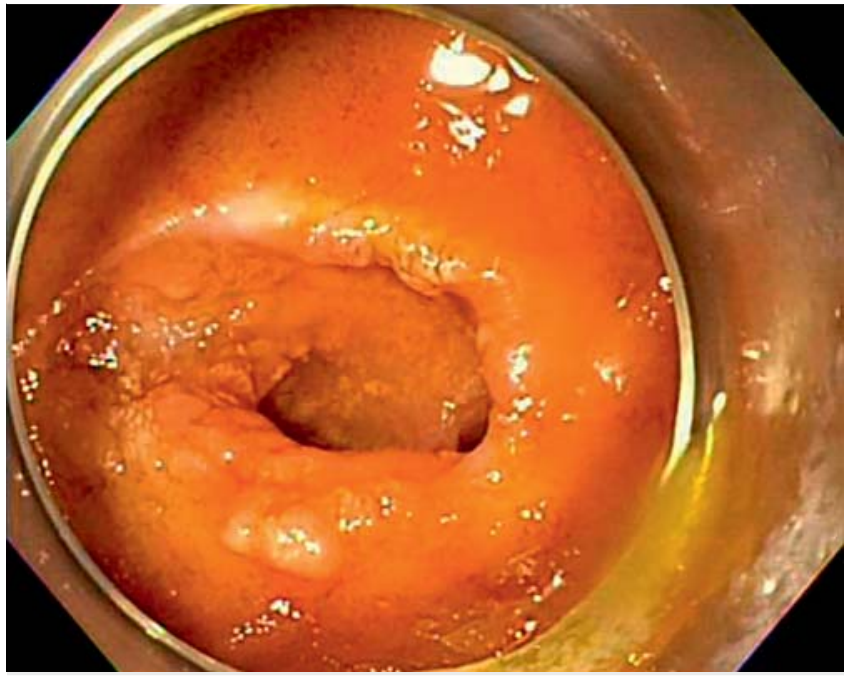

- Fig. 3 Endoscopic view using a $1 \mathrm{~T}$ therapeutic gastroscope with clear distal attachment cap showing the hepaticojejunal anastomosis.

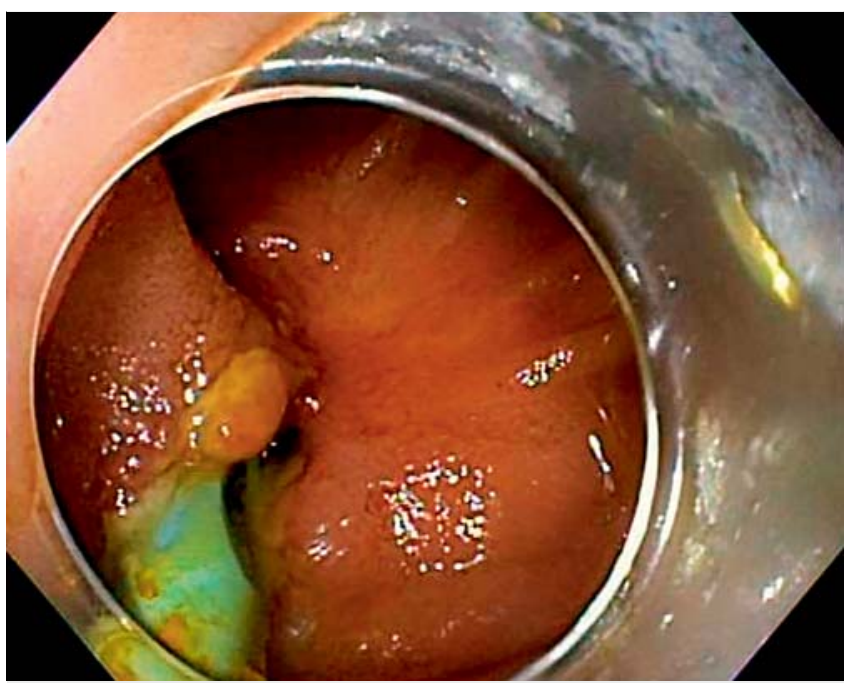

Fig. 4 Endoscopic view using a $1 \mathrm{~T}$ therapeutic gastroscope with clear distal attachment cap showing biliary drain from Interventional Radiology.

were obtained. Pathology of the biopsy specimen ultimately revealed tubular adenoma without dysplasia.

\section{Discussion}

Surgically altered anatomy including pancreaticoduodenectomy anatomy poses a unique challenge to ERCP. A variety of endoscopes have been employed for ERCP in pancreaticoduodenectomy, each with their own advantages and disadvantages. A traditional duodenoscope allows for a side-viewing angle which can be helpful to locate the hepaticojejunostomy. At $4.2 \mathrm{~mm}$, a duodenoscope offers the largest channel size of the endoscopes reviewed here. In addition, most common ERCP tools are designed for a traditional duodenoscope ( $\triangleright$ Table 1$)$. How-

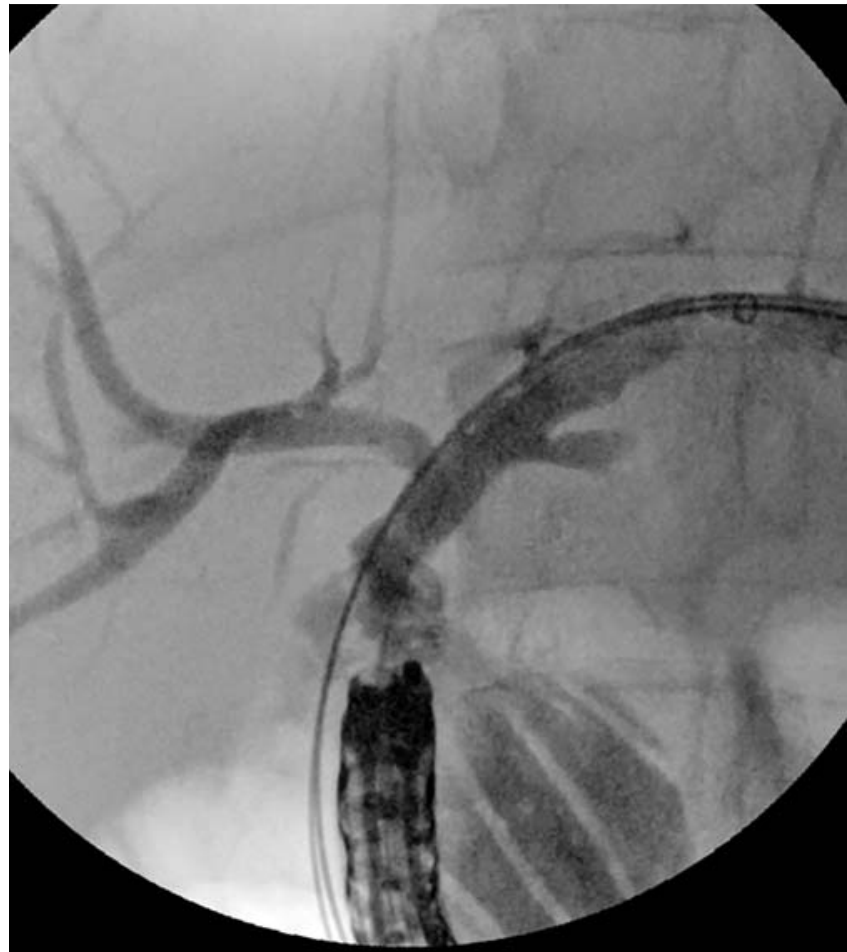

- Fig. 5 Fluoroscopic view of biliary cannulation through the hepaticojejunostomy via the modified $1 \mathrm{~T}$ therapeutic upper endoscope.

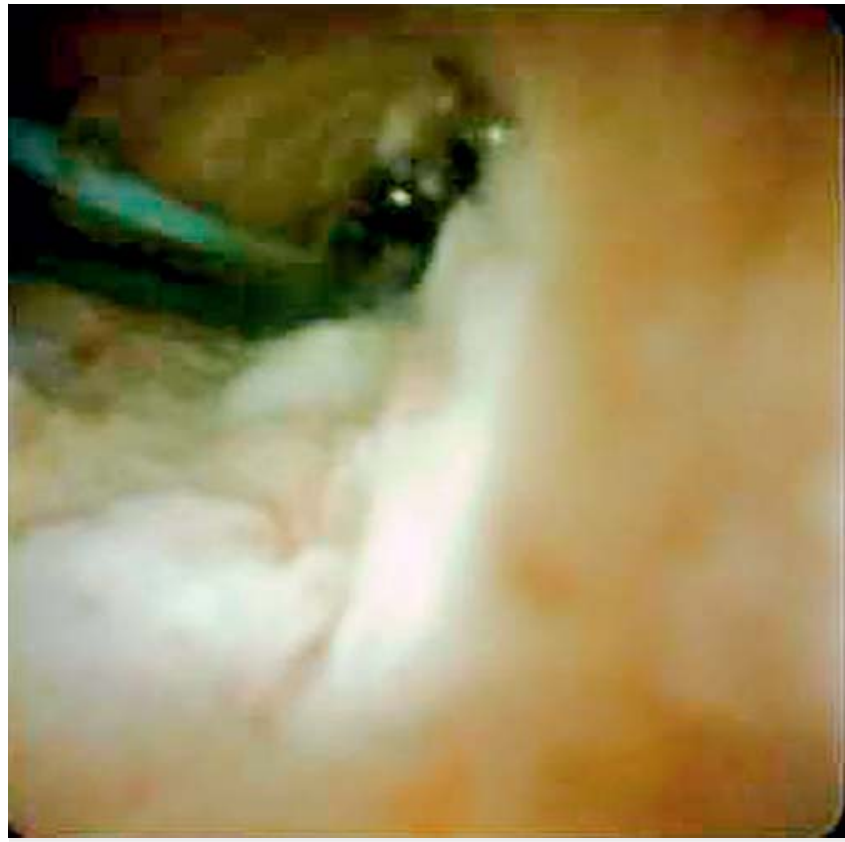

- Fig. 6 Cholangioscopy showing intraductal adenoma extending to the anastomosis.

ever, in patients with SAA including pancreaticoduodenectomy, it is often challenging to reach the biliary limb and the hepatico-jejunal anastomosis with a conventional duodenoscope. Potential reasons for this include length of biliary limb and acute angulations in the small intestine that are challenging to navi- 
- Table 1 Characteristics of various endoscopes used in ERCP in patients with pancreaticoduodenectomy.

\begin{tabular}{|c|c|c|c|c|c|}
\hline & $\begin{array}{l}\text { Duodenoscope } \\
\text { (Olympus TJF-Q190V) }\end{array}$ & $\begin{array}{l}\text { Pediatric colono- } \\
\text { scope (Olympus } \\
\text { PCF-PH190) }\end{array}$ & $\begin{array}{l}\text { Adult colonoscope } \\
\text { (Olympus CF-HQ190 L/I) }\end{array}$ & $\begin{array}{l}\text { Enteroscope } \\
\text { (SIF-Q180) }\end{array}$ & $\begin{array}{l}1 \mathrm{~T} \text { therapeutic endo- } \\
\text { scope (GIF-1TH190 } \\
\text { Olympus) }\end{array}$ \\
\hline Working length & $124 \mathrm{~cm}$ & $\begin{array}{l}168 \mathrm{~cm}(\mathrm{~L} \text { model }) \\
133(\text { I model })\end{array}$ & $\begin{array}{l}168 \mathrm{~cm} \text { (L model) } \\
133 \text { (I model) }\end{array}$ & $200 \mathrm{~cm}$ & $103 \mathrm{~cm}$ \\
\hline $\begin{array}{l}\text { Direction of } \\
\text { view }\end{array}$ & $\begin{array}{l}\text { Backward side viewing } \\
15^{\circ}\end{array}$ & Forward viewing & Forward viewing & Forward viewing & Forward viewing \\
\hline Channel size & $4.2 \mathrm{~mm}$ & $3.2 \mathrm{~mm}$ & $3.7 \mathrm{~mm}$ & $2.8 \mathrm{~mm}$ & $3.7 \mathrm{~mm}$ \\
\hline $\begin{array}{l}\text { Distal end } \\
\text { outer diameter }\end{array}$ & $13.5 \mathrm{~mm}$ & $9.7 \mathrm{~mm}$ & $13.2 \mathrm{~mm}$ & $9.2 \mathrm{~mm}$ & $10 \mathrm{~mm}$ \\
\hline $\begin{array}{l}\text { Maximum angu- } \\
\text { lation (upwards) }\end{array}$ & $120^{\circ}$ & $180^{\circ}$ & $180^{\circ}$ & $180^{\circ}$ & $210^{\circ}$ \\
\hline $\begin{array}{l}\text { Compatible ac- } \\
\text { cessories }\end{array}$ & $\begin{array}{l}\text { Fully-covered and } \\
\text { uncovered metal } \\
\text { biliary stents ( } 8 \mathrm{~mm} \\
\text { and } 10 \mathrm{~mm}) \\
\text { Plastic stents ( } 8.5 \mathrm{~F} \\
\text { and } 10 \mathrm{~F}) \\
\text { Biliary stone extrac- } \\
\text { tion balloon } \\
\text { Single-operator } \\
\text { cholangioscope }\end{array}$ & $\begin{array}{l}\text { 8.5F plastic stent } \\
\text { Biliary stone } \\
\text { extraction bal- } \\
\text { loon }\end{array}$ & $\begin{array}{l}\text { Plastic stents ( } 8.5 \mathrm{Fr} \text { and } \\
10 \mathrm{Fr}) \\
\text { Uncovered and fully-cover- } \\
\text { ed metal biliary stents } \\
(8 \mathrm{~mm} \text { and } 10 \mathrm{~mm}) \text { [ select } \\
\text { manufacturers] } \\
\text { Biliary stone extraction } \\
\text { balloon }\end{array}$ & $\begin{array}{l}\text { No standard } \\
\text { devices [Dedi- } \\
\text { cated devices] }\end{array}$ & $\begin{array}{l}\text { Fully-covered and } \\
\text { uncovered metal } \\
\text { biliary stents ( } 8 \mathrm{~F} \text { and } \\
10 \mathrm{~F}) \\
\text { Plastic stents ( } 8.5 \mathrm{~F} \\
\text { and } 10 \mathrm{~F}) \\
\text { Biliary stone extrac- } \\
\text { tion balloon } \\
\text { Single-operator } \\
\text { cholangioscope }\end{array}$ \\
\hline
\end{tabular}

gate with a side-viewing and relatively stiffer duodenoscope. This has led to use of adult and pediatric colonoscopes and balloon enteroscopy-assisted ERCP for performing ERCP in patients after pancreaticoduodenectomy.

Advantages of using pediatric and adult colonoscopes include having the largest endoscopic working length of the endoscopes reviewed here, which range from $133 \mathrm{~cm}$ to $168 \mathrm{~cm}$ depending on the model, a forward-viewing camera to aid in reaching the anastomosis, and variable stiffness, which can reduce looping. Disadvantages of the pediatric and adult colonoscopes include a smaller working channel $(3.2 \mathrm{~mm}$ versus $3.7 \mathrm{~mm}$ with the pediatric and adult colonoscope, respectively), inability to perform short wire technique, or passage of several accessories utilized in ERCP. While plastic stents and biliary stone extraction balloons are compatible with pediatric and adult colonoscopes, it is critical to consider endoscope working length as well as the distance from the biopsy port to the insertion tube of the endoscope; while a device may be long enough to reach the distal end of the colonoscope, it may have limited device working length compared to when used through a duodenoscope, which potentially could lead to situations in which the device might not be long enough to reach the proximal biliary tree. Similarly, the single balloon enteroscope has the advantage of a forward-viewing camera, ability to be advanced to longer lengths, and tip angulation similar to an adult or pediatric colonoscope. The disadvantages include less maneuverability, inability to perform short wire technique during $E R C P$, and a relatively smaller working channel $(2.8 \mathrm{~mm})$ that does not allow for utilization of several accessories needed in
ERCP such as stone extraction balloons, plastic biliary stents, or metal biliary stents. However, it is important to note that there are special dedicated accessories available that are compatible with the single balloon enteroscope. Those special devices allow for performing most interventions except for the use of a biliary stone extraction catheter and placement of a $10 \mathrm{~F}$ plastic stent. Table 1 summarizes the common accessories compatible with the previously mentioned endoscopes. The recent development of the modified therapeutic upper endoscope (1T endoscope) offers several advantages when performing ERCP in patients with pancreaticoduodenectomy anatomy. The previous iteration of the therapeutic gastroscope was limited by its lack of maneuverability due to its stiffness and larger diameter [10]. The $1 \mathrm{~T}$ endoscope offers a working length of $103 \mathrm{~cm}$, a channel size of $3.7 \mathrm{~mm}$, and it is forwardviewing. One of the main advantages is the increased maneuverability and a maximal upward angulation of $210^{\circ}$, the highest of all the endoscopes reviewed here ( $\triangleright$ Table 1 ). Due the endoscope length and working channel size, the $1 \mathrm{~T}$ endoscope can accommodate almost all the accessories that a conventional side-viewing duodenoscope can, including biliary stone extraction balloons, plastic biliary stents, and both uncovered and covered metal biliary stents. The conventional upper endoscope has previously been employed for ERCP in patients with surgically altered anatomy [11]. However, the conventional upper endoscope has a $2.8-\mathrm{mm}$ working channel, and several accessories used during ERCP are not compatible with that. In contrast, the $1 \mathrm{~T}$ endoscope's 3.7-mm working channel easily accommodates majority of accessories using in ERCP. The $1 \mathrm{~T}$ 
endoscope offers increased flexibility, which is helpful in navigating the small intestine. In addition, it can allow for using a short wire technique for performing ERCP. Finally, this is the only endoscope (apart from the conventional duodenoscope) from the ones mentioned previously that can be used to perform single-operator cholangioscopy (Boston Scientific, Marlborough, Massachusetts, United States) in patients with pancreaticoduodenectomy. Currently, in most patients with SAA who need single-operator cholangioscopy for exploration of the biliary tree, the most commonly utilized approach is cholangioscopy through a percutaneous biliary drain placed by an interventional radiologist prior to endoscopic intervention. The main limitation of the $1 \mathrm{~T}$ endoscope is the lack of an elevator and occasional inability to reach the biliary limb and hepaticojejunal anastomosis due to its length. While the $1 \mathrm{~T}$ endoscope can be helpful in these cases, it may not be able to reach the hepaticojejunostomy in some patients. In cases in which the $1 \mathrm{~T}$ endoscope fails, alternatives such as balloon-assisted ERCP or using a colonoscope for ERCP can be tried.

\section{Conclusions}

Here, we described two cases of patients with pancreaticoduodenectomy anatomy requiring ERCP for different indications successfully performed using a $1 \mathrm{~T}$ therapeutic gastroscope. In our practice, we use a distal attachment clear cap on the $1 \mathrm{~T}$ therapeutic gastroscope, which helps with engagement and cannulation of the hepaticojejunostomy. This approach has previously been described for balloon enteroscopy-assisted ERCP [9]. We prefer using this endoscope first because it allows us to determine if we can reach the biliary limb and hepaticojejunostomy in a short amount of time. Other tips that have been helpful in our practice include using minimal air or $\mathrm{CO}_{2}$ insufflation similar to colonoscopy, abdominal pressure in certain situations, and the use of suction to help in advancing the $1 \mathrm{~T}$ endoscope to the $\mathrm{HJ}$ anastomosis. We also use glucagon as necessary to help with small intestinal peristalsis. While the $1 \mathrm{~T}$ endoscope is not always successful in reaching the hepaticojejunostomy, it is useful to attempt, as almost all the accessories that are compatible with the traditional duodenoscope are compatible with the $1 \mathrm{~T}$ endoscope including $10 \mathrm{~F}$ plastic and metal stents. Our preliminary data suggest that using the modified therapeutic upper endoscope is a useful addition to the endoscopist toolbox while performing ERCP in patients post pancreaticoduodenectomy.

\section{Competing interests}

The authors declare that they have no conflict of interest.

\section{References}

[1] Kozarek RA. The past, present, and future of endoscopic retrograde cholangiopancreatography. Gastroenterol Hepatol 2017; 13: 620622

[2] Moreels TG. ERCP in the patient with surgically altered anatomy. Curr Gastroenterol Rep 2013; 15: 343

[3] Krutsri C, Kida M, Yamauchi H et al. Current status of endoscopic retrograde cholangiopancreatography in patients with surgically altered anatomy. World J Gastroenterol 2019; 25: 3313-3333

[4] Osnes M, Rosseland AR, Aabakken L. Endoscopic retrograde cholangiography and endoscopic papillotomy in patients with a previous Billroth-II resection. Gut 1986; 27: 1193-1198

[5] Park ET. Endoscopic retrograde cholangiopancreatography in bilioenteric anastomosis. Clin Endosc 2016; 49: 510-514

[6] Lichtenstein DR. Post-surgical Anatomy and ERCP. Tech Gastrointest Endosc 2007; 9: 114-124

[7] Chahal P, Baron TH, Topazian MD et al. Endoscopic retrograde cholangiopancreatography in post-Whipple patients. Endosc 2006; 38: 1241-1245

[8] Inamdar S, Slattery E, Sejpal D v et al. Systematic review and meta-analysis of single-balloon enteroscopy-assisted ERCP in patients with surgically altered GI anatomy. Gastrointest Endosc 2015; 82: 9-19

[9] Trindade AJ, Mella JM, Slattery E et al. Use of a cap in single-balloon enteroscopy-assisted endoscopic retrograde cholangiography. Endoscopy 2015; 47: 453-456

[10] Kodali VP, Petersen BT, Miller CA et al. A new jumbo-channel therapeutic gastroscope for acute upper gastrointestinal bleeding. Gastrointestinal endoscopy 1997; 45: 409-411

[11] Enestvedt BK, Kothari S, Pannala R et al. Devices and techniques for ERCP in the surgically altered GI tract. Gastrointest Endosc 2016; 83: 1061-1075 